\title{
HUBUNGAN PENGETAHUAN SIKAP DAN DUKUNGAN DENGAN TINGKAT KECEMASAN REMAJA PUTRI MENGHADAPI MENARCHE
}

\author{
Andriani \\ STIKes Payung Negeri Pekanbaru \\ Korespondensi: andriani.lecturer@gmail.com
}

\begin{abstract}
Background: Menarche in young women can cause anxiety. Many teenagers view menarche as a frightening thing, because menarche will cause discomfort, pain, dizziness and so on, Psychological symptoms to reject the physiological process. Anxiety is an excessive emotional reactivity, a dull depression, or a sensitive context, an emotional response. Purpose: The objective of the study was to understand the relationship of attitude knowledge and family support with the level of anxiety of adolescent girls. Methods: This research is quantitative type with anlitik design with coss sectional approach. The study was conducted in February April 2018. The sample in this study was female teenager amounting to 25 people. The sampling technique used is simple random sampling. The study was conducted using primary data obtained from the questionnaire, and univariate and bivariate analysis using chi-square statistical test. Results: From the result of research analysis of knowledge relationship with anxiety level got 15 respondents who have high knowledge of 8 people $(53,3 \%)$ with high level of anxiety and 7 people $(46,70 \%)$ with low level of anxiety. 13 respondents were positive attitude 6 people $(46,2 \%)$ with high level of anxiety and 7 people $(53,8 \%)$ with low level of anxiety. of 14 respondents who received family support and 7 people $(46.2 \%)$ with high anxiety level and 7 people (53.8\%) with low anxiety level. Conclusion: Based on the results of the study found no relationship of knowledge with anxiety level with $p$ value $0.742>\alpha 0.05$, Based on the results of the study found no relation attitude with anxiety level with $p$ value $0,529>\alpha 0.05$, Based on the results obtained did not there is a relationship of family support with anxiety level with $p$ value $0,495>\alpha$ 0,05 .
\end{abstract}

Keywords: Knowledge; Attitude; Family support; Anxiety level; Menarche

\begin{abstract}
ABSTRAK
Latar Belakang: Menarche yaitu haid pertama kali pada remaja putri dapat menimbulkan kecemasan. Banyak remaja memandang menarche adalah hal yang menakutkan, karena menarche akan menimbulkan ketidaknyamanan, sakit, pusing dan sebagainya, Gejala psikologis untuk menolak proses fisiologis tersebut. Kecemasan merupakan reaktivitas emosional berlebihan, depresi yang tumpul, atau konteks sensitif, respon emosional. Tujuan: Tujuan penelitian adalah untuk mengetuhui hubungan pengetahuan sikap dan dukungan keluarga dengan tingkat
\end{abstract}


kecemasan remaja putri. Metode: Penelitian ini berjenis kuantitatif dengan desain analitik dengan pendekatan cross sectional. Penelitian dilakukan pada bulan Februari - April 2018. sampel dalam penelitian ini adalah remaja putri yang berjumlah 25 orang. Teknik sampling yang digunakan adalah simple Random sampling. Penelitian dilakukan menggunakan data primer yang diperoleh dari kuesioner, dan analisis secara univariat dan bivariat menggunakan uji statistik chisquare. Hasil: Dari hasil analisis penelitian hubungan pengetahuan dengan tingkat kecemasan didapatkan 15 responden yang berpengetahuan tinggi 8 orang $(53,3 \%)$ dengan tingkat kecemasan yang tinggi dan 7 orang $(46,70 \%)$ dengan tingkat kecemasan yang rendah. 13 responden yang sikap positif 6 orang $(46,2 \%)$ dengan tingkat kecemasan yang tinggi dan 7 orang $(53,8 \%)$ dengan tingkat kecemasan yang rendah. dari 14 responden yang mendapat dukungan keluarga dan 7 orang $(46,2 \%)$ dengan tingkat kecemasan yang tinggi dan 7 orang $(53,8 \%)$ dengan tingkat kecemasan yang rendah. Kesimpulan: Berdasarkan hasil dari penelitian didapatkan tidak ada hubungan pengetahuan dengan tingkat kecemasan dengan $p$ value $0,742>\alpha 0,05$, Berdasarkan hasil dari penelitian didapatkan tidak ada hubungan sikap dengan tingkat kecemasan dengan $p$ value 0,529 $>\alpha 0,05$, Berdasarkan hasil dari penelitian didapatkan tidak ada hubungan dukungan keluarga dengan tingkat kecemasan dengan $p$ value $0,495>\alpha 0,05$.

\section{Kata Kunci: Pengetahuan; Sikap; Dukungan keluarga; Tingkat kecemasan; Menarche}

\section{PENDAHULUAN}

Remaja merupakan masa dimana peralihan dari masa anak-anak ke masa dewasa, yang telah meliputi semua perkembangan yang dialami sebagai persiapan memasuki masa dewasa. Perubahan perkembangan tersebut meliputi aspek fisik, psikis dan psikososial. Masa remaja merupakan salah satu periode dari perkembangan manusia. Remaja ialah masa perubahan atau peralihan dari anakanak ke masa dewasa yang meliputi perubahan biologis, perubahan psikologis, dan perubahan sosial (Sofia \& Adiyanti, 2013).

Remaja sebagai aset masa depan bangsa harus dipersiapkan dalam berbagai aspek. Peningkatan kualitas remaja dari segi pendidikan, kesehatan maupun keterlibatan secara ekonomi harus dilakukan sejak dini (BPS Jawa Timur, 2013). Berdasarkan Keputusan Menteri Kesehatan Republik Indonesia Nomor HK.02.02/ MENKES/52/2015 tentang Rencana Strategis Kementerian Kesehatan Tahun 2015-2019, salah satu sasaran strategis yang akan dicapai Kementerian Kesehatan adalah pembinaan ketahanan remaja. Indikator keberhasilan diukur dari peningkatan persentase pengetahuan dan pemahaman remaja tentang kesehatan reproduksi sebesar $75 \%$. 
Masa remaja akan dihadapkan dengan kematangan seksual yang disebut dengan fase pubertas. Remaja akan menghadapi perubahan baru dalam hidupnya. Hal ini membutuhkan penyesuaian secara mental . Perubahan bentuk tubuh dan kematangan seksual akan sangat berpengaruh pada kehidupan kejiwaan remaja. Penolakan biasa terjadi pada fase ini (Sulistyoningsih, 2014).

Menarche berasal dari Bahasa Yunani yakni mēn (bulan) dan arkhē (permulaan) adalah siklus menstruasi pertama, atau permulaan perdarahan menstruasi pertama, pada manusia wanita. Menarche adalah saat haid/menstruasi yang datang pertama kali pada seorang wanita yang sedang menginjak dewasa (Prawirohardjo, 2014).

Menurut Kusmiran (2014), menarche diartikan sebagai permulaan menstruasi pada seorang wanita pada masa pubertas, yang biasanya muncul pada usia 12 sampai 14 tahun. Perubahan penting terjadi pada masa remaja menuju wanita dewasa, menandakan bahwa anak tersebut sudah memasuki tahap kematangan organ seksual dalam tubuhnya.

Menarche terjadi pada usia 10-15 tahun, namun ada juga yang mengalami lebih cepat atau dibawah usia tersebut. Menarche yang terjadi sebelum usia 8 tahun disebut menstruasi precox (Prawirohardjo, 2014). Menurut Kemenkes RI (2018) umur kejadian menarche di Indonesia rata-rata terjadi pada umur 12,4 tahun dengan prevalensi $60 \%$, pada usia 9-10 tahun sebanyak 2,6\%, usia 11-12 tahun sebanyak $30,3 \%$, dan pada usia 13 tahun sebanyak $30 \%$. Sisanya mengalami menarche di atas umur 13 tahun.

Widyastuti (2014) menyatakan terdapat dua faktor terjadinya menarche yaitu faktor internal dan faktor eksternal. Faktor internal berupa status menarche ibu, berhubungan dengan percepatan atau perlambatan kejadian menarche yaitu status menarche ibu dengan kejadian menarche putrinya, faktor eksternal berupa lingkungan sosial, ekonomi, nutrisi, keterpaparan media masa pornografi, dan gaya hidup

Orang tua secara dini harus memberikan penjelasan tentang menarche pada anak perempuannya, agar anak lebih mengerti dan siap dalam menghadapi menarche. Umumnya anak perempuan akan memberi tahu ibunya saat menstruasi pertama kali, sayangnya tidak semua ibu memberikan informasi yang memadai 
kepada putrinya. Sebagian ibu enggan memberikan secara terbuka sampai remaja mengalami menstruasi pertama (menarche). Kondisi ini akan menimbulkan kecemasan pada anak, bahkan sering tidak menyenangkan atau serius. Akibanya, anak mengembangkan sikap negatif terhadap menstruasi pertama (menarche) dan melihatnya sebagai penyakit (Santrock, 2012).

Berdasarkan survei awal yang peneliti lakukan pada tanggal 25 januari 2018 di SDN 48, siswi kelas V didapatkan jumlah siswi 50 orang setelah dilakukan wawancara kepada 10 siswi, yang telah mengalami menarche sebanyak 4 siswi (40\%), dan 6 siswi (60\%) yang belum mengalami menarche. Dari 4 siswi yang telah mengalami menarche menyebutkan timbul perasaan cemas antara lain takut, khawatir dan gelisah karena tidak tahu dan tidak mengira akan mengalami menarche. Timbulnya kecemasan tersebut karena kurangnya pengetahuan tentang menarche. sikap, dan orang tua yang belum ada membicarakan masalah menarche tersebut ke anak putrinya. Sedangkan 6 siswi yang belum mengalami menarche merasa takut dan khawatir serta timbul perasan negatif lainnya karena mereka menyebutkan belum pernah mendapatkan penyuluhan tentang menarche.

Berdasarkan latar belakang tersebut, penelitian tertarik dan mengangkat masalah penelitian dengan judul :"Hubungan pengetahuan sikap dan dukungan keluarga dengan tingkat kecemasan remaja putri menghadapi menarche di SDN 48 tahun 2018".

\section{METODE}

Penelitian ini menggunakan jenis penelitian kuantitatif dan desain penelitiannya menggunakan penelitian Analitik dengan pendekatan cross sectional. Artinya tiap subjek dilakukan bersamaan. Penelitian ini bertujuan untuk hubungan pengetahuan sikap dan dukungan keluarga dengan tingkat kecemasan remaja putri menghadapi menarche di SDN 48 tahun 2018. Populasi adalah wilayah generalisasi yang terdiri atas objek/subjek yang mempunyai kuantitas dan karakteristik tertentu yang ditetapkan oleh peneliti untuk dipelajari dan kemudian ditarek kesimpulanya (Hidayat, 2014). Populasi dalam penelitian ini adalah seluruh remaja putri yang sudah menarche kelas VI di SDN 48 sebanyak 34 orang. 
Instrumen dalam penelitian ini adalah berupa kuesioner. Kuesioner ini dibuat oleh peneliti sendiri mengacu pada tinjauan teori yang telah ada, dengan cara pengisian angket (kuesioner) yang terdiri dari 30 pertanyaan, yaitu 10 pertanyaan untuk kuesioner pengetahuan, 10 pertanyaan untuk sikap, 10 untuk dukungan keluarga.

Di dalam penelitian ini Instrumen yang dapat digunakan untuk mengukur skala kecemasan adalah CMAS (childen's manifest anxiety scale) merupakan instrument yang dirancang untuk mengukur kecemasan anak dan remaja (6-19 tahun). Terdiri pengisian angket yang masing-masing membutuhkan jawabannya 'ya' dan 'tidak'. Tujuan adanya intrumen ini adalah menciptakan pengukuran yang obyektif untuk kecemasan anak secara berkelompok, menjaga waktu minimum agar penelitian valid dan akurat

\section{HASIL}

\section{Analisa Univariat}

Tabel 1. Distribusi Frekuensi Pengetahuan Menghadapi Menarche Pada Sisiwi di SDN 48 Pekanbaru

\begin{tabular}{cccc}
\hline No & Pengetahuan & Frekuensi & Presentasi \\
\hline 1 & Tinggi & 15 & $60 \%$ \\
2 & Rendah & 10 & $40 \%$ \\
\hline & Total & 25 & $100 \%$
\end{tabular}

Sumber : Analisis Data Primer Kuisioner

Dari tabel 1 dapat dilihat dari 25 remaja yang berada di SDN 48 Pekanbaru mayoritas oleh kondisi pengetahuan tinggi yaitu 60\% (15 orang).

Tabel 2. Distribusi Frekuensi Sikap Menghadapi Menarche Pada Sisiwi di SDN 48 Pekanbaru

\begin{tabular}{cccc}
\hline No & Sikap & Frekuensi & Prekuensi \\
\hline 1 & Positif & 13 & $52,0 \%$ \\
2 & Negatif & 12 & $48,0 \%$ \\
\hline & Total & 25 & $100 \%$ \\
\hline
\end{tabular}

Sumber : Analisis Data Primer Kuisioner

Dari tabel 2 dapat dilihat dari 25 remaja yang berada di SDN 48 Pekanbaru mayoritas oleh sikap positif sebanyak 52,0\% (13 orang). 
Tabel 3. Distribusi Frekuensi Dukungan Ibu Menghadapi Menarche Pada Sisiwi di SDN 48 Pekanbaru

\begin{tabular}{clcc}
\hline No & Dukungan Ibu & Frekuensi & Presentasi \\
\hline 1 & Mendukung & 14 & $56,0 \%$ \\
2 & Tidak Mendukung & 11 & $44,0 \%$ \\
\hline & Total & 25 & $100 \%$
\end{tabular}

Sumber : Analisis Data Primer Kuisioner

Dari tabel 3 dapat dilihat dari 25 remaja yang berada di SDN 48 Pekanbaru mayoritas adanya dukungan ibu sebanyak $56,0 \%$ (14 orang).

Tabel 4. Distribusi Frekuensi Tingkat Kecemasan Menghadapi Menarche Pada Siswi di SDN 48 Pekanbaru

\begin{tabular}{cccc}
\hline No & Tingkat Kecemasan & Frekuensi & Presentasi \\
\hline 1 & Cemas & 14 & $56,0 \%$ \\
2 & Tidak Cemas & 11 & $44,0 \%$ \\
\hline & Total & 25 & $100 \%$ \\
\hline
\end{tabular}

Sumber : Analisis Data Primer Kuisioner

Dari tabel 4 dapat dilihat dari 25 remaja yang berada di SDN 48 Pekanbaru mayoritas mengalami kecemasan sebanyak $56,0 \%$ (14 orang).

\section{Analisa Bivariat}

Tabel 5. Distribusi Frekuensi Hubungan Pengetahuan Siswi Dengan Tingkat Kecemasan Dalam Menghadapi Menerche di SDN 48 Pekanbaru

\begin{tabular}{cccccccccc}
\hline & & \multicolumn{3}{c}{ Tingkat Kecemasan } & \multirow{2}{*}{ Total } & \multirow{2}{*}{ P value } & $\alpha$ \\
\cline { 3 - 7 } No & Pengetahuan & \multicolumn{2}{c}{ Tinggi } & \multicolumn{2}{c}{ Rendah } & & & \\
\cline { 3 - 7 } & & $\mathrm{F}$ & $\%$ & $\mathrm{~F}$ & $\%$ & $\mathrm{~F}$ & $\%$ & & \\
\hline 1 & Tinggi & 8 & 32 & 7 & 28 & 15 & 60 & & \\
2 & Rendah & 6 & 24 & 4 & 16 & 10 & 40 & 0,74 & 0,05 \\
\hline & Total & 14 & 56 & 11 & 44 & 25 & 100 & & \\
\hline
\end{tabular}

Sumber : Analisis Data Primer Kuisioner

Berdasarkan dari tabel 5 dari 15 responden yang berpengetahuan tinggi 8 orang (32\%) dengan tingkat kecemasan yang tinggi dan 7 orang (28\%) dengan tingkat kecemasan yang rendah dan dari 10 responden yang berpengetahuan rendah 6 orang (24\%) dengan tingkat kecemasan tinggi dan 4 orang (16\%) dengan tingkat kecemasan rendah.

Pada uji statistik diperoleh $p$ value lebih besar 0,05 berarti tidak ada hubungan pengetahuan dengan tingkat kecemasan dalam menghadapi menerche. 
Tabel 6. Distribusi Frekuensi Hubungan Sikap Siswi Dengan Tingkat Kecemasan Dalam Menghadapi Menerche di SDN 48 Pekanbaru

\begin{tabular}{|c|c|c|c|c|c|c|c|c|c|}
\hline \multirow{3}{*}{ No } & \multirow{3}{*}{ Sikap } & \multicolumn{4}{|c|}{ Tingkat Kecemasan } & \multirow{2}{*}{\multicolumn{2}{|c|}{ Total }} & \multirow{3}{*}{$\mathrm{P}$ value } & \multirow{3}{*}{$\alpha$} \\
\hline & & \multicolumn{2}{|c|}{ Tinggi } & \multicolumn{2}{|c|}{ Rendah } & & & & \\
\hline & & $\mathrm{F}$ & $\%$ & $\mathrm{~F}$ & $\%$ & $\mathrm{~F}$ & $\%$ & & \\
\hline 1 & Positif & 6 & 24 & 7 & 28 & 13 & 52 & \multirow{3}{*}{0,529} & \multirow{3}{*}{0,05} \\
\hline 2 & Negatif & 8 & 32 & 4 & 16 & 12 & 48 & & \\
\hline & Total & 14 & 56 & 11 & 44 & 25 & 100 & & \\
\hline
\end{tabular}

Sumber : Analisis Data Primer Kuisioner

Berdasarkan dari tabel 6 dari 13 responden yang sikap positif 6 orang (24\%) dengan tingkat kecemasan yang tinggi dan 7 orang (28\%) dengan tingkat kecemasan yang rendah dan dari 12 responden yang sikap negatif 8 orang (32\%) dengan tingkat kecemasan yang tinggi dan 4 orang (16\%) dengan tingkat kecemasan yang rendah.

Pada uji statistik diperoleh $p$ value lebih besar 0,05 berarti tidak ada hubungan sikap dengan tingkat kecemasan dalam menghadapi menerche

Tabel 7. Distribusi Frekuensi Hubungan Dukungan Keluarga Siswi Dengan Tingkat Kecemasan Dalam Menghadapi Menerche di SDN 48 Pekanbaru

\begin{tabular}{|c|c|c|c|c|c|c|c|c|c|}
\hline \multirow{3}{*}{ No } & \multirow{3}{*}{$\begin{array}{l}\text { Dukungan } \\
\text { Orang Tua }\end{array}$} & \multicolumn{4}{|c|}{ Tingkat Kecemasan } & \multirow{2}{*}{\multicolumn{2}{|c|}{ Total }} & \multirow{3}{*}{$P$ value } & \multirow{3}{*}{$\alpha$} \\
\hline & & \multicolumn{2}{|c|}{ Tinggi } & \multicolumn{2}{|c|}{ Rendah } & & & & \\
\hline & & $\mathrm{F}$ & $\%$ & $\mathrm{~F}$ & $\%$ & $\mathrm{~F}$ & $\%$ & & \\
\hline 1 & Mendukung & 7 & 28 & 7 & 28 & 14 & 60 & & \\
\hline \multirow[t]{2}{*}{2} & $\begin{array}{l}\text { Tidak } \\
\text { Mendukung }\end{array}$ & 7 & 28 & 4 & 16 & 11 & 40 & 0,495 & 0,05 \\
\hline & & 14 & 56 & 11 & 44 & 25 & 100 & & \\
\hline
\end{tabular}

Sumber : Analisis Data Primer Kuisioner

Berdasarkan dari tabel 7 dari 14 responden yang mendapat dukungan keluarga 7 orang (28\%) dengan tingkat kecemasan yang tinggi dan 7 orang (28\%) dengan tingkat kecemasan yang rendah dan dari 11 responden yang tidak mendapat dukungan keluarga 7 orang (28\%) dengan tingkat kecemasan yang tinggi dan 4 orang $(16 \%)$ dengan tingkat kecemasan yang rendah.

Pada uji statistik diperoleh $p$ value lebih besar 0,05 berarti tidak ada hubungan dukungan keluarga dengan tingkat kecemasan dalam menghadapi menerche. 


\section{PEMBAHASAN}

Pengetahuan merupakan hasil dari tahu, dan ini terjadi setelah orang melakukan pengindraan terhadap suatu obyek tertentu. Pengindraan terjadi melalui pancaindra manusia, yakni indra penglihatan, pendengaran, penciuman, rasa, dan raba. Sebagian besar pengetahuan manusia diperoleh melalui mata dan telinga (Notoatmodja 2014)

Dari hasil penelitian di SDN 48 Pekanbaru menunjukan 25 responden sebagaian besar memiliki tingkat pengetahuan yang tinggi sebanyak $60 \%$. Hasil penelitian ini sejalan dengan yang dilakukan oleh Dwi Anggraini tahun 2016 yang berjudul hubungan pengetahuan tentang mentruasi dengan kecemasan menghadapi manarche pada siswi kelas V SD Muhammadiyah Wirobrajan 3 Yogyakarta bahwa mayoritas pengetahuan siswi cukup dengan tidak mengalami kecemasan sebanyak 20 responden $(40 \%)$.

Asumsi penelitian hal ini dikarenakan remaja putri di SDN 48 Pekanbaru mendapatkan informasi dari orangtua. Selain itu kesadaran/keinginan dari diri remaja putri yang baik untuk mencari tahu informasi yang lebih banyak tentang menarche. Baiknya minat untuk mencari tahu disebabkan karena keinginannya pengetahuan tentang menarche remaja putri dilingkungan sekitarnya.

Menurut Notoatmodjo (2014), sikap adalah merupakan reaksi atau respon seseorang yang masih terbuka dari seseorang terhadap stimulasi atau objek. Menurut Newcom dalam Notoatmodjo salah seorang ahli psikologis untuk bertindak, dan bukan merupakan pelaksanaan motif tertentu.

Hasil penelitian ini sesuai dengan teori Wawan, A (2011) yang menyatakan bahwa pengetahuan seseorang tentang suatu objek mengandung dua aspek, aspek positif dan aspek negatif. Kedua aspek ini yang akan menentukan sikap seseorang. Semakin banyak aspek positif dan objek yang diketahui, maka akan menimbulkan sikap makin positif terhadap objek tertentu.

Menurut asumsi penelitian, sikap remaja yang positif ini dikarenakan reaksi remaja yang ingin mengetahui tentang menarche sebagai fase / tahap baru yang akan dijalanin sebagai perubahan menuju masa dewasa telah mengambil atau menyita perhatian remaja untuk mencari tahu tentang menarche dan bersikaf dalam menghadapi masa tersebut. 
Sarwono (2012) mengatakan keluarga adalah lembaga pertama dan utama dalam melaksanakan proses sosialisasi. Perubahan yang terjadi saat menstruasi pertama (menarche) menyebabkan remaja menjadi canggung. Oleh karena itu remaja perlu mengadakan penyesuaian tingkah laku. Penyesuaian tersebut tidak dapat dilakukan dengan mulus, terutama jika tidak ada dukungan dari orang tua. Peran ibu sangat penting dalam proses pertumbuhan dan perkembangan anak, terutama pada masa remaja. Remaja mulai mengenal berbagai proses seksual yang sedang terjadi pada tubuh dan jiwanya pertama kali melalui ibu komunikasi yang efektif antara ibu dan anak akan membantu anak dalam menyesuaikan diri saat mengalami menstruasi pertama (menarche).

Hasil peneitian ini sejalan dengan yang dilakukan oleh Nila Wati yang berjudul hubungan Dukungan Ibu dengan kecemasan remaja dalam menghadapi menarche di SD negri Lomanis 01 kecamatan Cilacap Kabupaten Cilacap, bahwa dukungan ibu terhadap remaja dalam menghadapi menarche di SD Negri Lomanis 01 Kecemasan Cilacap tengan Kabupaten Cilacap Tahun 2013 62,2\% ibu mendukung anaknya menghadapi menarche dan 37,8\% ibu kurang mendukung.

Menurut asumsi penelitian dukungan keluarga memberikan dukungan yang positif terhadap responden dikarenakan keluarga telah menjalankan fungsinya dengan baik kepada setiap anggota keluarga. Adapun fungsi yang dijalankan oleh keluarga adalah fungsi efektif yang merupakan sumber kekuatan dasar serta pemenuhan kebutuhan psikologis dari keluarga untuk anggota keluarga lainnya.

Nainggolan dan Tambunan (2013), menyatakan bahwa kecemasan merupakan respon dari individu terhadap suatu keadaan yang tidak menyenangkan dan dialami oleh semua makhluk hidup dalam kehidupan sehari- hari dan digolongkan ke dalam pengalaman yang tidak menyenangkan. Perubahan psikologis pada rasa cemas yang dirasakan remaja seperti rasa terkejut bahkan trauma, rasa takut, bersikap irasional serta mudah tersinggung (Yolanda, Taufik dan Nurfarhanah, 2013)

Hasil penelitian ini sejalan dengan penelitian ini dilakukan oleh Ucik Lestiani yang bejudul Hubungan Tingkat Kecemasan dengan sikap dalam menghadapi menarche pada siswi kelas V di SD Wilayah Kecematan Karangnongko Kabupaten Sleman 2015 bahwa dari 50 responden memiliki tingkat kecemasan berat sekali 
(panik) 38\%, tidak ada kecemasan 14\%, menghadapi dan kecemasan ringan 36\%. Rata-rata siswi mengatakan perasaannya takut, perasaan gelisah sulit berkonsentrasi bahkan ada beberapa siswi yang mengatakan memiliki perasaan yang berubah-ubah atau tegang ketika mendengar kata menarche. Kecemasan pada individu dapat memberikan motivasi untuk mencapai sesuatu dan merupakan sumber penting dalam usaha memelihara keseimbangan hidup. Begitupun dengan pengalaman siswi mengenai menarche yang belum mereka ketahui sehingga mereka nampak cemas dalam menghadapinya

Hal ini sesuai dengan teori-teori yang ada, maka peneliti beramsumsi bahwa remaja putri mengalami kecemasan dalam menghadapi seperti menarche merasa bingung, takut, bad mood dan panik. Hal ini normal karena merupakan tahap penyesuaian diri pada remaja.

Hasil penelitian ini didukung oleh teori Widyasih dalam Jayanti (2012) bisa dikatakan bahwa pengetahuan mempunyai pengaruh yang tidak begitu kuat terhadap kesiapan seseorang dalam menghadapi menarche. Faktor-faktor yang mempengaruhi kesiapan seseorang menghadapi menarche diantaranya yaitu usia, perkembangan psikologi (kematang emosional), diwujudkan dengan pemberian informasi yang lebih banyak dan spesifik serta menanamkan anggapan yang benar tentang menarche sehingga dapat merubah anggapan siswi terhadap menstruasi bahwa menarche bukanlah hal yang menakutkan tatapi merupakan normal sehingga tidak perlu malu mengalaminya.

Peneliti berasumsi tingkat kecemasan dalam menghadapi menarche yaitu dikarenakan sebagian responden merasa tidak siap dengan kondisi menarche yang akan dilalui walaupun secara statistik memiliki tingkat pengetahuan yang baik.

Dari teori yang telah disebutkan dapat dijelaskan bahwa positif negatifnya sikap seseorang dipengaruhi oleh pemahaman atau pengetahuannya. Dalam menjelaskan Menarche sebaiknya remaja putri mendapatkan pengetahuan yang cukup sehingga remaja putri nantinya dapat bersikap sebagimana mestinya dan berperilaku yang sesuai pada saat menghadapi menarche.

Peneliti berasumsi tidak adanya hubungan sikap remaja putri dengan tingkat kecemasan dalam menghadapi menarche, dilihat dari sikap remaja yang positif dikarenakan adanya rasa ingin mencari tahu informasi dari orang tua tentang 
bagaimana cara menghadapi menarche. Namun tahap merasa cemas dengan persiapan menghadapi menarche masa menarche ataupun ada faktor lain yang lebih berhubungan terhadap rasa cemas dengan menghadapi menarche.

Peranan dan dukungan dari anggota keluarga yang diberikan kepada remaja akan mempengaruhi kecemasan remaja. Hal ini dikarenakan anggota keluarga merupakan orang yang paling dekat bagi remaja sehingga komunikasi pada hal-hal yang sensitif akan lebih terbuka. Keluarga berperan aktif dalam mengetahui kondisi remaja putri, baik fisik maupun psikologisnya karena keluarga bersifat saling ketergantungan satu anggota keluarga dengan anggota keluarga lainnya. Nainggolan dan Tambunan (2013)

Mardiah (2014) yang menyatakan Peran orang tua merupakan hal yang penting dalam pemberian perhatian dan informasi mengenai kesehatan reproduksi terkhusus tentang menarche yang akan lebih menambah informasi serta pengetahuan agar remaja putri lebih mengerti dan dapat menerima serta mengatasi permasalahan yang dialami saat menarche.

Hal ini didukung oleh penelitian yang dilakukan Abadi (2015) tentang hubungan dukungan keluarga dengan tingkat kecemasan remaja putri dalam mengahadapi menarche Menurut analisa peneliti, keluarga memberikan dukungan yang positif terhadap responden dikarenakan keluarga telah menjalankan fungsinya dengan baik kepada setiap anggota keluarganya.

Menurut asumsi penelitian tidak adanya hubungan dukungan keluarga dengan tingkat kecemasan dalam menghadapi menarche disebabkan karena dukungan keluarga belum cukup untuk mempengaruhi tingkat kecemasan remaja dalam menghadapi menarche. Mungkin faktor lain seperti teman sebaya atau lingkungan akan lebih berpengaruhi terhadap tingkat kecemasan. Pengalaman menghadapi menarche oleh teman sebaya atau lingkungan sekitar dianggap lebih jelas dan dapat diterima oleh remaja tanpa merasa ragu atau segan dan teman sebaya dianggap paling mengerti terhadap rasa cemas yang dihadapi oleh responden. 


\section{SIMPULAN DAN SARAN}

Dari Uraian diatas dapat disimpulkan bahwa responden di SDN 48 Pekanbaru mayoritas memiliki pengetahuan tinggi, sikap yang positif, adanya dukungan keluarga, tetapi memiliki tingkat kecemasan yang tinggi, dari hasil uji statistik menunjukkan Tidak ada hubungan antara pengetahuan, sikap, dukungan orang tua dengan tingkat kecemasan dalam menghadapi menarche pada responden di SDN 48 Pekanbaru.

Saran dari peneliti diharapkan Pihak Sekolah di SDN 48 Pekanbaru agar lebih memperhatikan remaja yang mengalami tingkat kecemasan yang tinggi terhadap menarche agar prestasi belajar tidak tergganggu serta tercapainya proses dan tujuan pendidikan. Upaya yang dapat dilakukan salah satunya dengan memberikan penyuluhan kesehatan seputar kesehatan reproduksi bagi remaja secara berkala dengan bekerja sama pada pihak Puskesmas atau Instansi pendidikan kesehatan.

\section{DAFTAR PUSTAKA}

Abadi dkk. (2015). Hubungan Dukungan Keluarga Dengan Tingkat Kecemasan Remaja Putri Dalam Mengahadapi Menarche. https://jom.unri.ac.id/index.php/JOMPSIK/article/view/8263/7934

Adiyanti, M. G., \& Sofia, A. (2013). Hubungan Pola Asuh Otoritaf Orang Tua Dan Konformitas Teman Sebaya Terhadap Kecerdasan Moral.

Anggraini, Dwi and Rohmah, Fathiyatur (2016) Hubungan Pengetahuan Tentang Menstruasi Dengan Kecemasan Menghadapi Menarche Pada Siswi Kelas V SD Muhammadiyah Wirobrajan 3 Yogyakarta. http://digilib.unisayogya.ac.id/1873/1/NASKAH\%20PUBLIKA $\underline{\text { SI.pdf }}$

Badan Pusat Statistik. 2013. Statistik Remaja Jawa Timur 2013. Surabaya: BPS Provinsi Jawa Timur.

Hidayat, Aziz Alimul. 2014. Metode Penelitian Kebidanan dan Teknik Analisis Data. Jakarta: Salemba Medika.

Kementerian Pendidikan dan Kebudayaan. 2015. Data Jumlah SD di Indonesia. Tersedia di: [diakses tanggal 5 Desember 2015].

Kusmiran, E. Kesehatan Reproduksi Remaja dan Wanita. Jakarta :SalembaMedika; 2014. 
Nainggolan, E., \& Tambunan, D. (2013). Tingkat kecemasan orang tua menghadapi perubahan perilaku remaja pada masa pubertas di kelurahan Balige 3 . Diperoleh tanggal 25 Desember 2014, dari http://www.akperhkbp.ac.id/wpcontent/uploads/2013/07/Jurnal- Keperawatan-Akper-HKBP-Balige-Vol- 1No-1.pdf

Notoatmodja, Soekidjo. 2014. Metode Penelitian Kesehatan. Jakarta: Rineka Cipta.

Prawirohardjo, Sarwono. 2014. Ilmu Kebidanan Sarwono Prawirohardjo. Jakarta: PT. Bina Pustaka Sarwono Prawirohardjo

Santrock, S. W. 2012. Psikologi Remaja. Jakarta: PT. Raja Grafindo Persada

Sarwono, 2012. Psikologi Remaja. Jakarta: Rajawali Pers.

Sulistioningsih, E. 2014. Hubungan Kesiapan Menghadapi Menarche dengan Perilaku Vulva Hygiene Remaja Putri di Sekolah Dasar Negeri (SDN) Kebonsari 04 Kecamatan Sumbersari Kabupaten Jember. Skripsi. Jember: Program Studi Ilmu Keperawatan Universitas Jember.

Lestari, Ucik and Rokhanawati, Dewi (2015), Hubungan Tingkat Kecemasan dengan sikap dalam menghadapi menarche pasa siawa kelas V di SD Wilayah Kecematan Karangnongko Kabupaten Sleman http://digilib.unisayogya.ac.id/797/

Wawan, A. 2011. Teori dan Pengukuran pengetahuan, Sikap, Dan perilaku Manusia. Yogyakarta: Niha Medika.

Widyasih, Suryani dalam Nur Fitri Jayanti, Sugi Purwanti (2012) Deskripsi FaktorFaktor Yang Mempengaruhi Kesiapan Anak Dalam Menghadapi Menarche Di Sd Negeri 1 Kretek Kecamatan Paguyangan Kabupaten Brebes Tahun 2011 http://ojs.akbidylpp.ac.id/index.php/Prada/article/viewFile/11/10

Widyastuti Y, Dkk. Kesehatan Reproduksi. Yogyakarta: Fitramaya. 2014

Yolanda, Taufik, \& Nurfarhanah. (2013). Hubungan antara pengetahuan tentang menarche dengan kecemasan siswi. Diperoleh tanggal 10 Oktober 2014, dari http://download.portalgaruda.org/article.p hp?article=24867\&val=153 